\title{
Produtos alternativos na proteção da videira contra o míldio
}

\author{
Vanessa Foresti Pereira(1), Mário Lúcio Vilela de Resende(1), Ana Cristina Andrade Monteiro(1), \\ Pedro Martins Ribeiro Júnior( ${ }^{(1)}$, Murillo de Albuquerque Regina ${ }^{(2)}$ e Fernanda Carvalho Lopes Medeiros ${ }^{(1)}$
}

(1)Universidade Federal de Lavras, Departamento de Fitopatologia, CEP 37200-000 Lavras, MG. E-mail: vanessaforesti@yahoo.com.br, mlucio@ufla.br, monteiroaca@yahoo.com.br, ribeirojuniorpm@yahoo.com.br fcalopes@hotmail.com (2)Empresa de Pesquisa Agropecuária de Minas Gerais, Núcleo Tecnológico Epamig Uva e Vinho, CEP 37780-000 Caldas, MG. E-mail: murillo@epamigcaldas.gov.br

Resumo - O objetivo deste trabalho foi avaliar a eficiência de produtos alternativos na proteção da videira (Vitis vinifera) contra o míldio (Plasmopara viticola), bem como determinar a influência desses produtos na qualidade dos frutos da cultivar Merlot. Para o controle da doença, foram utilizados produtos à base de extratos vegetais, manano-oligossacarídeos fosforilados, fosfitos e acibenzolar-S-metil, além de fungicidas tradicionais. A intensidade do míldio em folhas e cachos, a produtividade, o número total de cachos por parcela, o peso médio do cacho e baga e as características analíticas do mosto foram avaliados nas safras de 2007/2008 e 2008/2009. Os fosfitos proporcionaram proteção contra o míldio da videira, com produtividade semelhante à do tratamento com fungicidas tradicionais. Os tratamentos baseados em manano-oligossacarídeos fosforilados, acibenzolar-S-metil e extratos vegetais não apresentaram controle eficiente do míldio. Os produtos alternativos testados não influenciam a qualidade analítica dos frutos, mas proporcionam, em geral, peso médio de cachos e de bagas menor que o do tratamento com fungicidas.

Termos para indexação: Plasmopara viticola, Vitis vinifera, extratos vegetais, fosfitos.

\section{Alternative products for the protection of vine against downy mildew}

\begin{abstract}
The objective of this work was to evaluate the efficiency of alternative products for the protection of vine (Vitis vinifera) against downy mildew (Plasmopara viticola), and to determine the influence of these products on the quality of Merlot cultivar grapes. Products based on plant extracts, phosphorylated mannanoligosaccharides, phosphites and acibenzolar-S-methyl, besides traditional fungicides, were used for the disease control. The intensity of downy mildew on leaves and bunches, productivity, total number of bunches per plot, average weight of bunch and berry and analytical characteristics of grapes were assessed during the 2007/2008 and 2008/2009 seasons. Phosphites provided protection against downy mildew, and the yield was similar that of to the treatment with traditional fungicides. Treatments based on phosphorylated mannanoligosaccharides, acibenzolar-S-methyl and plant extracts showed no effective control of downy mildew. The alternative products tested do not influence the analytical quality of the grapes, but generally provide lower average weight of bunches and berries than the treatment with fungicides.
\end{abstract}

Index terms: Plasmopara viticola, Vitis vinifera, plant extracts, phosphites.

\section{Introdução}

Entre as doenças de maior importância para a viticultura, o míldio [Plasmopara viticola (Berk. \& Curt) Berl. \& de Toni] é o responsável pelos maiores danos (Garrido et al., 2004). As perdas com o míldio, quando ocorre elevada precipitação durante o desenvolvimento vegetativo da planta, podem atingir $100 \%$, o que torna essa enfermidade, que também tem efeito sobre a qualidade de frutos, uma das maiores restrições à produção de uvas no Brasil e no mundo (Madden et al., 2000).
A pulverização com fungicidas e a utilização de cultivares resistentes, quando disponíveis, são alguns dos métodos usualmente recomendados para o manejo do míldio (Amorim \& Kuniyuki, 2005). O método de controle adotado com maior frequência pelos produtores é a pulverização com fungicidas de contato e sistêmicos (Sônego \& Garrido, 2005), que requerem diversas aplicações durante o ciclo de crescimento e produção da videira (Madden et al., 2000).

Compostos como ácido salicílico e acibenzolar-S-metil são capazes de induzir a resistência sistêmica contra um amplo espectro de patógenos, 
como vírus, bactérias e fungos, em várias espécies de plantas (Sticher et al., 1997). Formulações à base de extratos vegetais, como extratos de casca de café e de folhas de café infectadas com ferrugem, também têm sido utilizadas para indução de resistência sistêmica em mudas (Pereira et al., 2008a, 2008b). Santos et al. (2007) observaram que o extrato aquoso de folhas de café com ferrugem reduziu a incidência da cercosporiose, da mancha-de-phoma e da ferrugem em relação aos percentuais de doença observados nas testemunhas pulverizadas com a calda Viça Café.

Produtos contendo nutrientes como os fosfitos vêm sendo utilizados no controle de doenças de plantas, inclusive de fruteiras de clima temperado (Reuveni et al., 1994; Sônego \& Garrido, 2005; Sautter et al., 2008). Em videira, esses produtos mostraram-se eficientes no controle de míldio (Dalbó \& Schuck, 2003), com resultados similares aos proporcionados pelo uso de fungicidas (Sonego \& Garrido, 2005). Apesar do modo de ação dos fosfitos não ter sido elucidado com exatidão, alguns trabalhos demonstraram que eles agem sobre o patógeno diretamente ou indiretamente pela indução de resistência sistêmica na planta, com a indução da síntese de fitoalexinas, compostos fenólicos em geral e proteínas relacionadas à patogênese (Fenn \& Coffey, 1984; Jackson et al., 2000; Daniel \& Guest, 2005; Sautter et al., 2008).

Produtos derivados de microrganismos, também têm sido utilizados no controle alternativo de doenças de plantas, como o Agro-Mos, à base de manano-oligossacarídeos fosforilados, proveniente da parede celular de Saccharomyces cerevisiae, biocomplexados com cobre, enxofre e zinco. Dantas et al. (2004) avaliaram o potencial do acibenzolar-S-metil e do Agro-Mos na proteção de frutos de mamão contra podridões e observaram que os dois indutores são eficazes no controle dessas doenças. Costa (2008) verificou que o Agro-Mos reduz a incidência da vassoura-de-bruxa em mudas de cacaueiro, com eficiência similar à do fungicida cúprico Recop. Rosa et al. (2007) observaram que o Agro-Mos, em mistura com alguns fertilizantes, é capaz de reduzir a severidade do míldio em videiras da cultivar Isabel.

O objetivo deste trabalho foi avaliar a eficiência de produtos alternativos à base de extratos vegetais, manano-oligossacarídeos fosforilados, fosfitos e acibenzolar-S-metil, na proteção da videira contra o míldio, bem como determinar a influência desses produtos na qualidade de uvas da cultivar Merlot.

\section{Material e Métodos}

Foram realizados dois experimentos em campo, um na safra de 2007/2008 e outro na de 2008/2009, no Núcleo Tecnológico Epamig Uva e Vinho, em Caldas, MG.

Para obtençãodos extratos de folhas de café infectadas com ferrugem (EFID), folhas de café contaminadas com Hemileia vastatrix, coletadas da superfície do solo de lavoura cafeeira, foram inicialmente desidratadas em estufa, a $60^{\circ} \mathrm{C}$ por 48 horas, e moídas até a obtenção de pó fino. Posteriormente, $100 \mathrm{~g}$ desse pó foram misturados com $1.000 \mathrm{~mL}$ de água destilada, e fervidos por duas horas em refluxo. Em seguida, a suspensão foi filtrada em peneira de 400 mesh. $\mathrm{O}$ extrato obtido foi armazenado em freezer, a $-20^{\circ} \mathrm{C}$, até o momento das pulverizações.

Para a obtenção do extrato de casca de uva (ECU), foram utilizadas cascas de bagas de uvas sadias e doentes, obtidas por ocasião do final da colheita de um pomar de uva da cultivar Merlot. As uvas foram desidratadas em estufa ventilada, por 72 horas a $60^{\circ} \mathrm{C}$. Após a desidratação, as cascas foram moídas até a obtenção de pó fino. Em seguida, $100 \mathrm{~g}$ de cascas moídas foram misturadas com $1.000 \mathrm{~mL}$ de água destilada e fervidas por duas horas em refluxo. A suspensão foi, então, filtrada em peneira de 400 mesh, e o extrato obtido ao final do processo foi armazenado em freezer, a $-20^{\circ} \mathrm{C}$, até o momento das pulverizações.

O Agro-Mos (Improcrop do Brasil, Curitiba, PR) é composto por manano-oligossacarídeos fosforilados provenientes da parede celular de Saccharomyces cerevisiae biocomplexados com $35 \mathrm{~g} \mathrm{~L}^{-1}$ de Cu, 27,5 $\mathrm{g} \mathrm{L}^{-1}$ de S e $25 \mathrm{~g} \mathrm{~L}^{-1}$ de $\mathrm{Zn}$.

Com relação aos fosfitos, foram utilizados fosfito de cobre Fulland (Sudoeste Fertilizantes Ltda., Araxá, $\mathrm{MG}$ ), que continham em sua formulação $53,6 \mathrm{~g} \mathrm{~L}^{-1}$ de $\mathrm{Cu}$ e $268 \mathrm{~g} \mathrm{~L}^{-1}$ de $\mathrm{P}_{2} \mathrm{O}_{5}$, e também os fosfitos de potássio Reforce $\left(240 \mathrm{~g} \mathrm{~L}^{-1}\right.$ de $\mathrm{K}_{2} \mathrm{O}$ e $340 \mathrm{~g} \mathrm{~L}^{-1}$ de $\mathrm{P}_{2} \mathrm{O}_{5}$; Agrichem do Brasil Ltda., Ribeirão Preto, SP) e Reforce + AS $\left(240 \mathrm{~g} \mathrm{~L}^{-1}\right.$ de $\mathrm{K}_{2} \mathrm{O}, 340 \mathrm{~g} \mathrm{~L}^{-1}$ de $\mathrm{P}_{2} \mathrm{O}_{5}$ e 5\% de ácido salicílico; Agrichem do Brasil Ltda., Ribeirão Preto, SP), além do Nutri Phite (403,26 g L-1 de $\mathrm{K}_{2} \mathrm{O}$ e $434,28 \mathrm{~g} \mathrm{~L}^{-1}$ de $\mathrm{P}_{2} \mathrm{O}_{5}$; Iharabras S.A. Indústrias Químicas, Sorocaba, SP) e do Pepfós $\left(280 \mathrm{~g} \mathrm{~L}^{-1}\right.$ de K$_{2} \mathrm{O}$ e $420 \mathrm{~g} \mathrm{~L}^{-1}$ de $\mathrm{P}_{2} \mathrm{O}_{5}$; Pepita Fertilizantes Ltda.; Poços de Caldas, MG).

Foram utilizados também o Bion $(50 \%$ de acibenzolar-S-metil; Syngenta Proteção de Cultivos Ltda., Paulínia, SP) e o AS (ácido salicílico P.A.; Merck, 
Darmstadt, Alemanha), além dos fungicidas Cabrio Top (metiram $550 \mathrm{~g} \mathrm{~kg}^{-1}$ e piraclostrobina $50 \mathrm{~g} \mathrm{~kg}^{-1}$; BASF S.A., São Paulo, SP), Daconil (clorotalonil $500 \mathrm{~g} \mathrm{~L}^{-1}$; Syngenta Proteção de Cultivos Ltda., Paulínia, SP) e Ridomil (metalaxil-M $40 \mathrm{~g} \mathrm{~kg}^{-1}$ e mancozeb $640 \mathrm{~g} \mathrm{~kg}^{-1}$; Syngenta Proteção de Cultivos Ltda., Paulínia, SP).

Para se verificar o efeito desses produtos no controle do míldio, foi utilizada a cultivar de Vitis vinifera Merlot (Clone 343), com cinco anos de idade, enxertada sobre o porta-enxerto 1103 Paulsen, plantada em espaçamento de $2,5 \times 1,5 \mathrm{~m}$, e conduzida em espaldeira com três fios de arame. As plantas foram conduzidas em duplo cordão esporonado (sistema Royat), podadas com poda curta (duas gemas) e permaneceram com 20 a 22 gemas, o que resultou em um total de 50 a $55 \mathrm{mil}$ gemas por hectare.

No primeiro experimento, conduzido no período de 27/11/2007 a 17/2/2008, foram utilizados: Agro-Mos (3 $\left.\mathrm{mL} \mathrm{L}^{-1}\right)$, Fulland $\left(5 \mathrm{~mL} \mathrm{~L}^{-1}\right)$, Reforce $\left(6 \mathrm{~mL} \mathrm{~L}^{-1}\right)$, Reforce + AS $\left(6 \mathrm{~mL} \mathrm{~L}^{-1}\right)$, Pepfós $\left(6 \mathrm{~mL} \mathrm{~L}^{-1}\right)$, ácido salicílico $\left(0,3 \mathrm{~g} \mathrm{~L}^{-1}\right)$, EFID e ECU. Foi utilizado, também, um tratamento químico padrão, com a pulverização, de forma alternada, dos fungicidas Cabrio Top $\left(2 \mathrm{~g} \mathrm{~L}^{-1}\right)$, Daconil $\left(2 \mathrm{~g} \mathrm{~L}^{-1}\right)$ e Ridomil (2,5 $\left.\mathrm{g} \mathrm{L} \mathrm{L}^{-1}\right)$, e uma testemunha sem pulverização. O delineamento utilizado foi o de blocos ao acaso, com quatro repetições de seis plantas em linha por parcela, com parcela útil formada pelas quatro plantas centrais da linha de plantio. Foi utilizada também bordadura de uma linha, entre as linhas que receberam pulverização com os tratamentos.

As pulverizações foram realizadas a partir das brotações das videiras, em intervalos semanais, no total de 12 aplicações, realizadas com pulverizador costal manual, até o ponto de escorrimento. Foi adicionado à calda de pulverização $0,05 \%$ de óleo mineral, e o volume aplicado variou de 700 a $1.000 \mathrm{~L} \mathrm{ha}^{-1}$, de acordo com o estágio de desenvolvimento da planta.

A severidade do míldio nas folhas foi avaliada quinzenalmente - no total de quatro avaliações até o momento da colheita -, após o início dos primeiros sintomas, em 27/12/2007, na primeira safra, e em 29/12/2008, na segunda safra. Para tanto, foi utilizada a escala de notas proposta por Azevedo (1997), com algumas alterações. A severidade do míldio foi avaliada em toda a planta, dentro da parcela útil, utilizando uma escala com notas que variaram de 0 (ausência de doença) a 5 (mais de $50 \%$ da planta com área foliar doente). A partir dos resultados dessas avaliações, foram calculados os níveis de severidade e foi determinada a área abaixo da curva de progresso da severidade do míldio (AACPS), assim como a plotagem das curvas de progresso da doença em relação ao tempo. Nos cachos, foi realizada apenas uma avaliação de incidência do míldio. Os índices de controle do míldio foram obtidos pela relação 1 - (x/y), em que $\mathrm{x}$ representa $\mathrm{o}$ índice da doença das plantas tratadas e y representa o índice de doença da testemunha (Li et al., 1996).

O segundo experimento foi conduzido no período de 17/10/2008 a 10/2/2009, em outro parreiral, nas mesmas condições do primeiro experimento. Para tanto, foram utilizados os produtos que proporcionaram maior controle do míldio no primeiro experimento, em duas dosagens: Reforce $\left(4,5\right.$ e $\left.6 \mathrm{~mL} \mathrm{~L}^{-1}\right)$ e Pepfós $\left(3\right.$ e $\left.6 \mathrm{~mL} \mathrm{~L}^{-1}\right)$. Além desses, foram utilizados também o Nutri Phite $(3 \mathrm{e}$ $\left.6 \mathrm{~mL} \mathrm{~L}^{-1}\right)$, o Bion $\left(0,2\right.$ e $\left.0,4 \mathrm{~g} \mathrm{~L}^{-1}\right)$, um tratamento padrão químico com os fungicidas Cabrio Top $\left(2 \mathrm{~g} \mathrm{~L}^{-1}\right)$, Daconil $\left(2 \mathrm{~g} \mathrm{~L}^{-1}\right)$ e Ridomil $\left(2,5 \mathrm{~g} \mathrm{~L}^{-1}\right)$, aplicados de forma alternada, e uma testemunha sem pulverização. $\mathrm{O}$ delineamento utilizado foi o mesmo do primeiro experimento.

Além das avaliações fitopatológicas, realizadas conforme descrito no primeiro experimento, no segundo experimento também foram realizadas as seguintes avaliações de produtividade e de qualidade da baga: quilogramas por parcela; número total de cachos por parcela; peso médio do cacho e da baga; teor de sólidos solúveis totais ( ${ }^{\circ}$ Brix), pelo método de Lane-Enyon (Association of Official Analytical Chemists, 1990), determinado por meio do refratômetro portátil; acidez titulável total, mensurada por meio de titulação com $\mathrm{NaOH} 0,1 \mathrm{~N}$ e fenolftaleína como indicador, seguindo a técnica descrita na Association of Official Analytical Chemists (1990); e avaliação do $\mathrm{pH}$ por meio de medidor de $\mathrm{pH}$. Essas avaliações não foram realizadas na safra de 2007/2008, em razão do precoce e intenso ataque de pássaros e insetos às bagas, principalmente nos tratamentos com menor eficiência no controle do míldio. Para evitar que o mesmo ocorresse na safra de 2008/2009, os cachos foram cobertos com tecido do tipo filó, no estádio de pintor (início da maturação).

Os dados de AACPS do míldio nas folhas e de incidência nos cachos (transformados para arc sen $\mathrm{x}^{0,5}$ ), bem como os de produção e de características analíticas dos frutos, foram submetidos à análise de variância utilizando-se o programa Sisvar (Ferreira, 2003). As médias foram comparadas pelo teste de Scott-Knott, a $5 \%$ de probabilidade. 


\section{Resultados e Discussão}

Na safra de 2007/2008, as pulverizações com os fosfitos de potássio Reforce e Pepfós proporcionaram menor severidade do míldio nas folhas das videiras (Tabela 1). Esses tratamentos proporcionaram AACPS inferior até mesmo à de plantas pulverizadas com o tratamento químico padrão com fungicidas. Pulverizações com Reforce + AS e Fulland (fosfito de cobre) não diferiram entre si nem do tratamento com fungicidas. Plantas tratadas com Agro-Mos apresentaram AACPS intermediária, inferior à dos tratamentos com ácido salicílico e EFID, que foram inferiores à constatada nos tratamentos ECU e testemunha sem pulverização. Esses resultados corroboram os obtidos por Sônego et al. (2003), que observaram controle do míldio de 97\%, em folhas e cachos, pela aplicação de fosfito de potássio em videira da cultivar Cabernet Sauvignon, desempenho superior ao proporcionado pelo fungicida cimoxanil + manebe.

As pulverizações com Agro-Mos, AS e com os extratos vegetais (EFID e ECU) mostraram baixa eficiência na redução da severidade do míldio da videira, uma vez que proporcionaram maiores
AACPS em folhas e alta incidência da doença nos cachos (Tabela 1). Esse resultado, provavelmente, foi influenciado pelo excesso de chuvas ocorrido entre 27/11/2007 de e 17/2/2008, o qual, atingindo o valor total de $685,9 \mathrm{~mm}$ e coincidindo com alguns períodos do experimento, foi extremamente favorável à epidemia do míldio. Alguns autores mostram que produtos alternativos como Agro-Mos e extratos de alga e biomassa cítrica apresentam baixa eficiência no controle do míldio da videira, principalmente sob alta incidência de chuvas (Peruch et al., 2007; Rosa et al., 2007).

Pela análise do progresso do míldio no decorrer das avaliações, no primeiro experimento (Figura $1 \mathrm{~A}$ ), observa-se que ocorre a formação de três grupos de tratamentos, de acordo com a severidade da doença: o primeiro, com menor severidade, é formado pelos fosfitos e fungicidas; o segundo, pelo Agro-Mos; e o terceiro grupo, que apresentou maior severidade do míldio nas folhas, pelos extratos vegetais, ácido salicílico e testemunha. Nessa mesma safra, observou-se que, nos cachos, os fosfitos de potássio Pepfós e Reforce + AS proporcionaram baixa incidência de míldio, semelhante à do tratamento padrão com fungicidas (Tabela 1).

Tabela 1. Efeito dos tratamentos na área abaixo da curva de progresso da severidade (AACPS) do míldio nas folhas e na incidência do míldio nos cachos de videira cv. Merlot, com os respectivos índices de controle, nas safras de 2007/2008 e $2008 / 2009^{(1)}$.

\begin{tabular}{|c|c|c|c|c|}
\hline \multirow[t]{2}{*}{ Tratamento $^{(2)}$} & \multicolumn{2}{|c|}{ Folhas } & \multicolumn{2}{|c|}{ Cachos } \\
\hline & AACPS & Controle $(\%)$ & Incidência $^{(3)}$ & Controle $(\%)$ \\
\hline & \multicolumn{4}{|c|}{ Safra 2007/2008 } \\
\hline Reforce $\left(6 \mathrm{~mL} \mathrm{~L}^{-1}\right)$ & $550,0 \mathrm{a}$ & 82,4 & $18,3 \mathrm{~b}$ & 79,8 \\
\hline Pepfós $\left(6 \mathrm{~mL} \mathrm{~L}^{-1}\right)$ & $625,0 \mathrm{a}$ & 80,0 & $0,0 \mathrm{a}$ & 100,0 \\
\hline Reforce + Ácido salicílico $\left(6 \mathrm{~mL} \mathrm{~L}^{-1}\right)$ & $800,0 \mathrm{~b}$ & 74,4 & $7,9 \mathrm{a}$ & 91,2 \\
\hline Fungicidas & $900,0 \mathrm{~b}$ & 71,2 & $3,8 \mathrm{a}$ & 95,8 \\
\hline Fulland $\left(5 \mathrm{~mL} \mathrm{~L}^{-1}\right)$ & $1.100,0 \mathrm{~b}$ & 64,8 & $33,5 b$ & 63,1 \\
\hline Agro-Mos $\left(3 \mathrm{~mL} \mathrm{~L}^{-1}\right)$ & $2.137,0 \mathrm{c}$ & 31,6 & $64,0 \mathrm{c}$ & 28,8 \\
\hline Ácido salicílico $\left(0,3 \mathrm{~g} \mathrm{~L}^{-1}\right)$ & $2.687,5 \mathrm{~d}$ & 14,0 & $80,9 c$ & 10,9 \\
\hline EFID & $2.750,0 \mathrm{~d}$ & 12,0 & $100,0 \mathrm{~d}$ & 0,0 \\
\hline $\mathrm{ECU}$ & $3.012,5 \mathrm{e}$ & 3,6 & $72,0 \mathrm{c}$ & 20,7 \\
\hline Testemunha & $3.125,0 \mathrm{e}$ & - & $90,8 \mathrm{~d}$ & - \\
\hline \multirow[t]{2}{*}{$\mathrm{CV}(\%)$} & 11,3 & & 20,40 & \\
\hline & \multicolumn{4}{|c|}{ Safra 2008/2009 } \\
\hline Pepfós $\left(6\right.$ mL L $\left.{ }^{-1}\right)$ & $1.112,5 \mathrm{a}$ & 66,7 & $0,0 \mathrm{a}$ & 100,0 \\
\hline Fungicidas & $1.250,0 \mathrm{a}$ & 62,5 & $3,7 \mathrm{a}$ & 96,3 \\
\hline Reforce $\left(4,5 \mathrm{~mL} \mathrm{~L}^{-1}\right)$ & $1.362,5 \mathrm{a}$ & 59,2 & $5,2 \mathrm{a}$ & 94,8 \\
\hline Reforce $\left(6 \mathrm{~mL} \mathrm{~L}^{-1}\right)$ & $1.462,5 b$ & 56,2 & $3,5 \mathrm{a}$ & 96,5 \\
\hline Nutri Phite $\left(6 \mathrm{~mL} \mathrm{~L}^{-1}\right)$ & $1.562,5 \mathrm{~b}$ & 53,2 & $1,5 \mathrm{a}$ & 98,5 \\
\hline Nutri Phite $\left(3 \mathrm{~mL} \mathrm{~L}^{-1}\right)$ & $1.550,0 \mathrm{~b}$ & 53,6 & $4,0 \mathrm{a}$ & 96,0 \\
\hline Pepfós $\left(3 \mathrm{~mL} \mathrm{~L}^{-1}\right)$ & $1.712,5 b$ & 48,7 & $12,5 \mathrm{a}$ & 87,5 \\
\hline Bion $\left(0,2 \mathrm{~g} \mathrm{~L}^{-1}\right)$ & $2.500,0 \mathrm{c}$ & 25,1 & $61,0 \mathrm{~b}$ & 39,0 \\
\hline Bion $\left(0,4 \mathrm{~g} \mathrm{~L}^{-1}\right)$ & $2.562,5 \mathrm{c}$ & 23,2 & $62,5 b$ & 37,5 \\
\hline Testemunha & $3.337,5 \mathrm{~d}$ & - & $100,0 \mathrm{c}$ & - \\
\hline CV (\%) & 10,51 & & 28,55 & \\
\hline
\end{tabular}


Os tratamentos Reforce e Fulland proporcionaram incidência intermediária dessa doença nos cachos. Esses dados apontam para a eficiência dos fosfitos de potássio no controle de doenças causadas por oomicetos.

$\mathrm{Na}$ safra de 2008/2009, observou-se menor severidade do míldio nas folhas de videira pulverizadas com Pepfós $6 \mathrm{~mL} \mathrm{~L}^{-1}$, com o tratamento padrão com
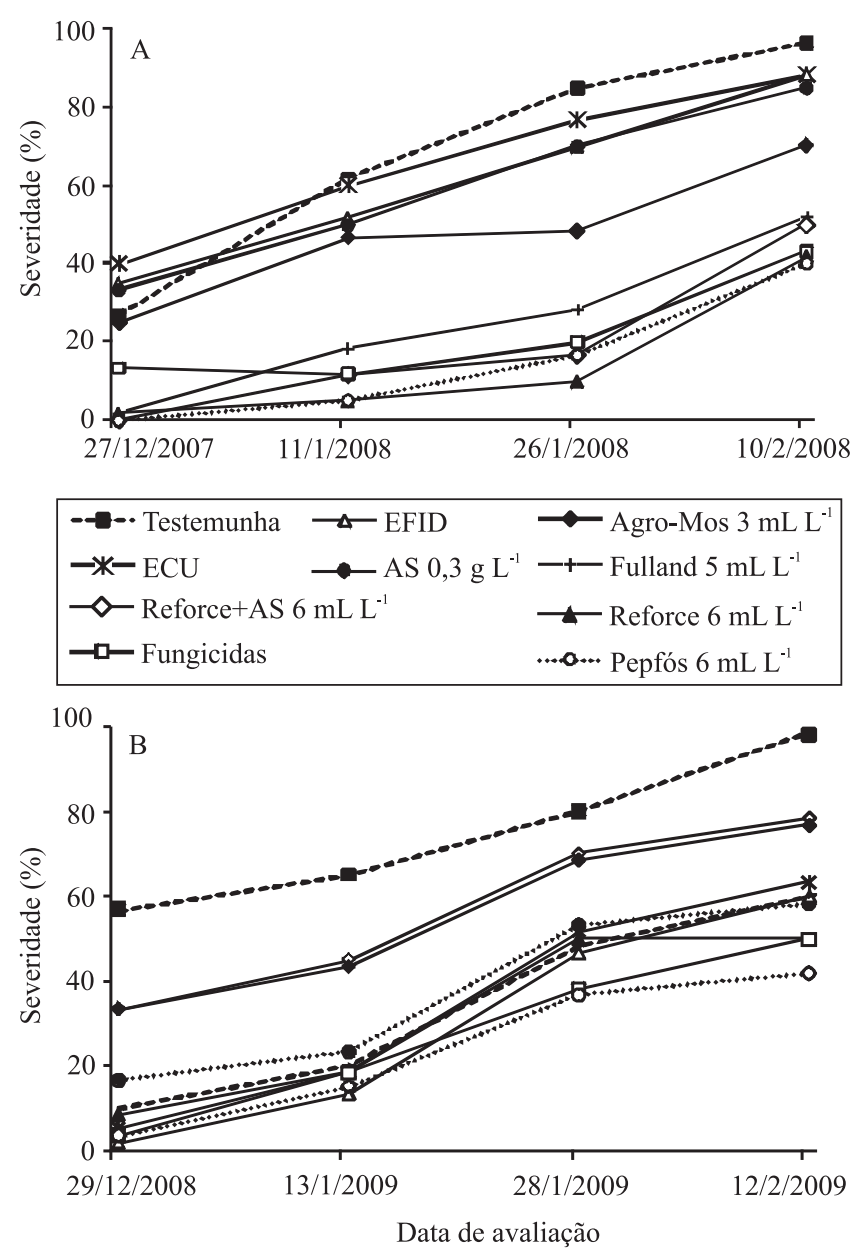

\begin{tabular}{|c|c|}
\hline$-\rightarrow--$ Testemunha & $\multimap$ Bion $0,2 \mathrm{~g} \mathrm{~L}^{-1}$ \\
\hline$\multimap$ Bion $0,4 \mathrm{~g} \mathrm{~L}^{-1}$ & $\multimap$ Nutri Phite $6 \mathrm{~mL} \mathrm{~L}^{-1}$ \\
\hline - Nutri Phite $3 \mathrm{~mL} \mathrm{~L}^{-1}$ & $\rightarrow \square$ Fungicidas \\
\hline$\multimap$ Reforce $6 \mathrm{~mL} \mathrm{~L}^{-1}$ & …… Pepfós $6 \mathrm{~mL} \mathrm{~L}^{-1}$ \\
\hline …… Pepfós $3 \mathrm{~mL} \mathrm{~L}^{-1}$ & $\neg-$ Reforce $4,5 \mathrm{~mL} \mathrm{~L}^{-1}$ \\
\hline
\end{tabular}

Figura 1. Efeito dos tratamentos no progresso da severidade do míldio da videira, nas safras de 2007/2008 (A) e 2008/2009 (B). AS - ácido salicílico, EFID - extratos de folhas de café infectadas com ferrugem; ECU - extrato de casca de uva; fungicidas - fungicidas em aplicação alternada (Cabrio Top, Daconil e Ridonil). Foram realizadas 12 pulverizações, com intervalo de uma semana entre elas. fungicidas e com Reforce 4,5 $\mathrm{mL} \mathrm{L}^{-1}$ (Tabela 1). Essa severidade foi inferior à dos tratamentos com Reforce $6 \mathrm{~mL} \mathrm{~L}^{-1}$, com as duas doses de Nutri Phite utilizadas e com Pepfós $3 \mathrm{~mL} \mathrm{~L}^{-1}$. Pelo progresso da doença no decorrer das avaliações ao longo da safra de 2008/2009, pode-se observar que os tratamentos com fosfitos proporcionaram, em média, menor severidade do míldio da videira (Figura 1 B). Nos cachos, observou-se que todos os fosfitos foram eficientes no controle e propiciaram baixa incidência da doença, diferindo estatisticamente da testemunha e dos demais tratamentos (Tabela 1).

$\mathrm{O}$ tratamento químico padrão com fungicidas e o tratamento com Nutri Phite $6 \mathrm{~mL} \mathrm{~L}^{-1}$ proporcionaram maior produtividade nas parcelas e maior número de cachos (Tabela 2). Em geral, os fosfitos, em todas as doses utilizadas, proporcionaram maiores pesos médios das bagas, superiores aos dos tratamentos com Bion e à testemunha.

Osfosfitos proporcionaram, emmédia, maiorproteção das videiras contra o míldio, tanto nas folhas como nos cachos. Resultados semelhantes foram observados por Peruch et al. (2007), que verificaram redução de $71 \%$ da área abaixo da curva de progresso do míldio em folhas de videira ao usar o fosfito de potássio. Sônego \& Garrido (2005) relatam que a maioria dos fosfitos apresenta controle equivalente, ou até melhor, ao proporcionado por fungicidas normalmente utilizados para o controle de míldio da videira. Porém, a eficácia desses produtos, tanto em folhas quanto em cachos, varia em função da concentração de nutrientes e doses utilizadas. Os fosfitos, além de ativar o sistema de defesa das plantas, atuam diretamente sobre o patógeno (Jackson et al., 2000).

No presente trabalho, os tratamentos com extratos vegetais (EFID e ECU), Bion e ácido salicílico proporcionaram menor eficiência no controle do míldio da videira, tanto em folhas quanto em cachos, com índices de doença inferiores apenas aos da testemunha. Cole (1999) não observou efeito direto do Bion sobre os patógenos. Wordell Filho et al. (2007) não constataram eficiência desse eliciador contra o míldio (Peronospora destructor) em cebola, com somente $30,1 \%$ de controle obtido.

Para a qualidade analítica dos frutos, não se verificou efeito significativo dos tratamentos nos teores de sólidos solúveis totais, nem no pH do mosto. Entretanto, todos os tratamentos resultaram em menor acidez titulável 
Tabela 2. Efeito dos tratamentos na produtividade, no número de cachos, no peso médio de cachos e no peso médio de bagas de videira cv. Merlot, na safra de 2008/2009(1).

\begin{tabular}{|c|c|c|c|c|}
\hline Tratamento & Produtividade $\left(\mathrm{kg}\right.$ parcela $\left.{ }^{-1}\right)$ & $\mathrm{N}^{\underline{0}}$ cachos por parcela & Peso médio de cachos $(\mathrm{g})$ & Peso médio de bagas (g) \\
\hline$\overline{\text { Pepfós }\left(6 \mathrm{~mL} \mathrm{~L}^{-1}\right)}$ & $1,3 b$ & $12,2 \mathrm{~b}$ & $89,5 \mathrm{a}$ & $1,95 \mathrm{a}$ \\
\hline Fungicidas & $2,8 \mathrm{a}$ & $23,7 \mathrm{a}$ & $116,0 \mathrm{a}$ & $1,78 \mathrm{a}$ \\
\hline Reforce $\left(4,5 \mathrm{~mL} \mathrm{~L} \mathrm{~L}^{-1}\right)$ & $1,0 \mathrm{~b}$ & $16,0 \mathrm{~b}$ & $62,7 \mathrm{~b}$ & $2,10 \mathrm{a}$ \\
\hline Reforce $\left(6 \mathrm{~mL} \mathrm{~L}^{-1}\right)$ & $1,0 \mathrm{~b}$ & $15,5 b$ & $70,5 b$ & $1,69 \mathrm{a}$ \\
\hline Nutri Phite $\left(6 \mathrm{~mL} \mathrm{~L}^{-1}\right)$ & $2,2 \mathrm{a}$ & $26,7 a$ & $78,7 b$ & $1,75 \mathrm{a}$ \\
\hline Nutri Phite $\left(3 \mathrm{~mL} \mathrm{~L}^{-1}\right)$ & $1,2 b$ & $18,0 \mathrm{~b}$ & $68,5 b$ & $1,85 \mathrm{a}$ \\
\hline Pepfós $\left(3 \mathrm{~mL} \mathrm{~L}^{-1}\right)$ & $0,8 b$ & $12,0 \mathrm{~b}$ & $65,5 b$ & $1,93 \mathrm{a}$ \\
\hline Bion $\left(0,2 \mathrm{~g} \mathrm{~L}^{-1}\right)$ & $0,6 \mathrm{~b}$ & $18,7 \mathrm{~b}$ & $31,2 \mathrm{c}$ & $1,33 b$ \\
\hline Bion $\left(0,4 \mathrm{~g} \mathrm{~L}^{-1}\right)$ & $0,6 b$ & $17,1 b$ & $38,7 \mathrm{c}$ & $1,53 \mathrm{~b}$ \\
\hline Testemunha & $0,2 b$ & $15,5 \mathrm{~b}$ & $12,5 \mathrm{c}$ & $1,59 \mathrm{~b}$ \\
\hline $\mathrm{CV}(\%)$ & 49,24 & 35,63 & 29,67 & 10,04 \\
\hline
\end{tabular}

${ }^{(1)}$ Médias seguidas de letras iguais não diferem entre si pelo teste de Scott-Knott, a 5\% de probabilidade.

Tabela 3. Efeito dos tratamentos nas características analíticas do mosto de bagas de videira cv. Merlot, na safra de $2008 / 2009^{(1)}$

\begin{tabular}{lccc}
\hline Tratamento & $\begin{array}{c}\text { Sólidos solúveis } \\
\text { totais }\left({ }^{\circ} \text { Brix }\right)\end{array}$ & $\begin{array}{c}\text { Acidez titulável } \\
\text { total }\left(\mathrm{meq} \mathrm{L}^{-1}\right)\end{array}$ & $\mathrm{pH}$ \\
\hline Testemunha & $17,2 \mathrm{a}$ & $145,6 \mathrm{a}$ & $3,3 \mathrm{a}$ \\
Pepfós $\left(3 \mathrm{~mL} \mathrm{~L}^{-1}\right)$ & $16,5 \mathrm{a}$ & $121,9 \mathrm{~b}$ & $3,2 \mathrm{a}$ \\
Bion $\left(0,4 \mathrm{~g} \mathrm{~L}^{-1}\right)$ & $16,4 \mathrm{a}$ & $128,4 \mathrm{~b}$ & $3,2 \mathrm{a}$ \\
Bion $\left(0,2 \mathrm{~g} \mathrm{~L}^{-1}\right)$ & $16,2 \mathrm{a}$ & $127,5 \mathrm{~b}$ & $3,2 \mathrm{a}$ \\
Reforce $\left(6 \mathrm{~mL} \mathrm{~L}^{-1}\right)$ & $16,1 \mathrm{a}$ & $120,0 \mathrm{~b}$ & $3,3 \mathrm{a}$ \\
Nutri Phite $\left(6 \mathrm{~mL} \mathrm{~L}^{-1}\right)$ & $15,9 \mathrm{a}$ & $118,1 \mathrm{~b}$ & $3,2 \mathrm{a}$ \\
Reforce $\left(4,5 \mathrm{~mL} \mathrm{~L}^{-1}\right)$ & $15,9 \mathrm{a}$ & $123,1 \mathrm{~b}$ & $3,2 \mathrm{a}$ \\
Pepfós $\left(6 \mathrm{~mL} \mathrm{~L}^{-1}\right)$ & $15,9 \mathrm{a}$ & $121,3 \mathrm{~b}$ & $3,3 \mathrm{a}$ \\
Nutri Phite $\left(3 \mathrm{~mL} \mathrm{~L}^{-1}\right)$ & $15,8 \mathrm{a}$ & $119,4 \mathrm{~b}$ & $3,2 \mathrm{a}$ \\
Fungicidas & $15,5 \mathrm{a}$ & $124,4 \mathrm{~b}$ & $3,2 \mathrm{a}$ \\
\hline CV $(\%)$ & 3,45 & 6,31 & 1,30
\end{tabular}

${ }^{(1)}$ Médias seguidas de letras iguais não diferem entre si pelo teste de ScottKnott, a 5\% de probabilidade.

total que a da testemunha (Tabela 3), devido ao fato de terem proporcionado menor intensidade da doença nos cachos. De acordo com Jackson \& Lombard (1993) e Sônego et al. (2005), a ocorrência contínua de dias chuvosos associada a elevadas temperaturas, além de interferir diretamente na incidência de doenças foliares, facilita a ocorrência de elevado número de podridões dos cachos, eleva o $\mathrm{pH}$ e a acidez do mosto.

A qualidade do mosto está relacionada, entre outros fatores, ao grau de enfolhamento das plantas, ao total de cachos e à influência da quantidade de chuva e doenças (Càstino, 1992). Segundo Rizzon \& Miele (2003), o mosto da cultivar Merlot pronto para vinificação deve apresentar teor de $18,4^{\circ} \mathrm{Brix}$, acidez total de $104 \mathrm{meq} \mathrm{L}^{-1}$ e pH 3,21. No presente trabalho, os tratamentos não influenciaram a qualidade do mosto, que, no entanto, foi proveniente de frutos colhidos antes da época indicada. Os valores de ${ }^{\circ}$ Brix apresentaram-se pouco abaixo do nível ideal. Regina et al. (2006), mencionam que as cultivares tintas podem apresentar maiores dificuldades em atingir um ponto ideal de maturação, quando em condições de verão chuvoso, como o observado neste experimento, na safra de 2008/2009 no qual ocorreu uma precipitação total de $848,4 \mathrm{~mm}$, desde $17 / 10 / 2008$ até $10 / 2 / 2009$.

\section{Conclusões}

1. Q fosfitos, Pepfós, Reforce e Nutri Phite, controlam o míldio em folhas e cachos de videira com a mesma eficiência do tratamento com fungicidas.

2. O tratamentos com Agro-Mos (mananooligossacarídeo fosforilado), extrato de folha de cafeeiro com ferrugem, extrato de casca de uva e Bion (acibenzolar-S-metil) não apresentam boa eficiência na proteção da videira contra o míldio.

3. Os produtos testados não influenciam a qualidade analítica dos frutos, mas, em geral, proporcionam menor peso médio de cachos e de bagas que o tratamento com fungicidas.

\section{Agradecimentos}

À Fundação de Amparo à Pesquisa do Estado de Minas Gerais, pelo apoio financeiro; ao Conselho Nacional de Desenvolvimento Científico e Tecnológico, pela concessão da bolsa; e à Empresa de Pesquisa Agropecuária de Minas Gerais, pelo suporte técnico.

\section{Referências}

AMORIM, L.; KUNIYUKI, H. Doenças da videira. In: KIMATI, H.; AMORIM, L.; REZENDE, J.A.M.; BERGAMIM FILHO, A.; CAMARGO, L.E.A. (Ed.). Manual de fitopatologia: doenças de plantas cultivadas. 4.ed. São Paulo: Agronômica Ceres, 2005. v.2, p.639-651. 
ASSOCIATION OF OFFICIAL ANALYTICAL CHEMISTS. Official methods of analysis of the Association of Official Analytical Chemists. $15^{\text {th }}$ ed. Washington: AOAC, 1990. 684p.

AZEVEDO, L.A.S. de. Manual de quantificação de doenças de plantas. São Paulo: Ciba Agro e Novartis, 1997. 114p.

CÀSTINO, M. La qualità dell'uva. Vini d'Italia, v.34, p.23-40, 1992.

COLE, D.L. The efficacy of acibenzolar-S-methyl, an inducer of systemic acquired resistance, against bacterial and fungal diseases of tobacco. Crop Protection, v.18, p.267-273, 1999.

COSTA, J.C.B. Novos indutores de resistência no manejo da Vassoura-de-bruxa (Crinipellis perniciosa) do cacaueiro (Theobroma cacao L.). 2008. 84p. Tese (Doutorado) - Universidade Federal de Lavras, Lavras.

DALBÓ, M.A.; SCHUCK, E. Avaliação do uso de fosfitos para o controle do míldio da videira. Agropecuária Catarinense, v.16, p.33-36, 2003.

DANIEL, R.; GUEST, D. Defence responses induced by potassium phosphonate in Phytophthora palmivora-challenged Arabidopsis thaliana. Physiological and Molecular Plant Pathology, v.67, p.194-201, 2005.

DANTAS, S.A.F.; OLIVEIRA, S.M.A.; BEZERRA NETO, E.; COELHO, R.S.B.C.; SILVA, R.L.X. da. Indutores de resistência na proteção do mamão contra podridões pós-colheita. Summa Phytopathologica, v.30, p.314-319, 2004.

FENN,F.E.; COFFEY,M.D. Studies on the In Vitro and In Vivo antifungal activity of Fosethyl-Al and Phosphorous Acid. Phytopathology, v.74, p.606-611, 1984.

FERREIRA, D.F. Sisvar. Versão 4.2. Lavras: UFLA, 2003.

GARRIDO, L. da R.; SÔNEGO, O.R.; GOMES, V.N. Fungos associados com o declínio e morte de videiras no Estado do Rio Grande do Sul. Fitopatologia Brasileira, v.29, p.322-324, 2004.

JACKSON, D.I.; LOMBARD, P.B. Environmental and management practices affecting grape composition and wine quality - a review. American Journal of Enology and Viticulture, v.44, p.409-430, 1993.

JACKSON, T.J.; BURGESS, T.; COLQUHOUN, I.; HARDY, G.E.S.T.J. Action of the fungicide phosphite on Eucalyptus marginata inoculated with Phytophthora cinnamomi. Plant Pathology, v.49, p.147-154, 2000 .

LI, J.; ZINGEN-SELL, I.; BUCHENAUER, H. Induction of resistance of cotton plants to Verticillium wilt and of tomato plants to Fusarium wilt by 3-aminobutyric acid and methyl jasmonate. Journal of Plant Diseases and Plant Protection, v.103, p.288-299, 1996.

MADDEN, L.V.; ELLIS, M.A.; LALANCETTE, N.; HUGHES, G.; WILSON, L.L. Evaluation of a disease warning system for downy mildew of grapes. Plant Disease, v.84, p.549-554, 2000.

PEREIRA, R.B.; ALVES, E.; RIBEIRO JÚNIOR, P.M.; RESENDE, M.L.V de; LUCAS, G.C.; FERREIRA, J.B. Extrato de casca de café, óleo essencial de tomilho e acibenzolar-S-metil no manejo da cercosporiose-do-cafeeiro. Pesquisa Agropecuária Brasileira, v.43, p.1287-1296, 2008a.

PEREIRA, R.B.; RESENDE, M.L.V. de; RIBEIRO JÚNIOR, P.M.; AMARAL, D.R.; LUCAS, G.C.; CAVALCANTI, F.R. Ativação de defesa em cacaueiro contra a murcha-de-verticílio por extratos naturais e acibenzolar-S-metil. Pesquisa Agropecuária Brasileira, v.43, p.171-178, 2008b.

PERUCH, L.A.M.; MEDEIROS, A.M.; BRUNA, E.D; STADINIK, M. Biomassa cítrica, extrato de algas, calda bordalesa e fosfitos no controle do míldio da videira, cv. Niágara Branca. Revista de Ciências Agroveterinárias, v.6, p.143-148, 2007.

REGINA, M. de A.; SOUZA, C.M. de; AMORIM, D.A. de; FÁVERO, A.C.; PEREIRA, G.E. Avaliação de híbridos de videira destinados à elaboração de vinhos brancos em Caldas, Minas Gerais. Revista Brasileira de Fruticultura, v.28, p.262-266, 2006.

REUVENI, M.; NAOR, A.; REUVENI, R.; SHIMONI, M.; BRAVDO, B. The influence of NPK fertilization rates on susceptibility to powdery mildew of field-grown winegrapes. Journal of Small Fruit and Viticulture, v.2, p.31-41, 1994.

RIZZON, L.A.; MIELE, A. Avaliação da cv. Merlot para elaboração de vinho tinto. Ciência e Tecnologia de Alimentos, v.23, p.156-161, 2003.

ROSA, R.C.T. da; COELHO, R.S.B.; TAVARES, S.C.C. de H.; CAVALCANTI, V.A.L.B. Efeito de indutores no controle de míldio em Vitis labrusca. Summa Phytopathologica, v.33, p.68-73, 2007.

SANTOS, F.S.; SOUZA, P.E.; RESENDE, M.L.V.; POZZA, E.A.; MIRANDA, J.C.; RIBEIRO JÚNIOR, P.M.; MANERBA, F.C. Efeito de extratos vegetais no progresso de doenças foliares do cafeeiro orgânico. Fitopatologia Brasileira, v.32, p.59-63, 2007.

SAUTTER, C.K.; STORCK, L.; RIZZATI, M.R.; MALLMANN, C.A.; BRACKMANN, A. Síntese de trans-resveratrol e controle de podridão em maçãs com uso de elicitores em pós-colheita. Pesquisa Agropecuária Brasileira, v.43, p.1097-1103, 2008.

SÔNEGO, O.R.; GARRIDO, L. da R. Avaliação da eficácia de algumas marcas comerciais de fosfito de potássio e de fosfonato de potássio no controle do míldio da videira. Bento Gonçalves : Embrapa Uva e Vinho, 2005. 13p. (Embrapa Uva e Vinho. Circular técnica, 60).

SÔNEGO, O.R.; GARRIDO, L. da R.; CZERMAINSKI, A.B.C. Avaliação de fosfitos no controle do míldio da videira. Bento Gonçalves: Embrapa Uva e Vinho, 2003. 18p. (Embrapa Uva e Vinho. Boletim de pesquisa e desenvolvimento, 11).

SÔNEGO, O.R.; GARRIDO, L. da R.; GRIGOLETTI JÚNIOR, A. Principais doenças fúngicas da videira no Sul do Brasil. Bento Gonçalves: Embrapa Uva e Vinho, 2005. 25p. (Embrapa Uva e Vinho. Circular técnica, 56).

STICHER, L.; MAUCH-MANI, B.; MÉTRAUX, J.P. Systemic acquired resistance. Annual Review of Phytopathology, v.35, p.235-270, 1997.

WORDELLFILHO, J.A.; MARTINS, D.A.; STADNIK, M.J.Aplicação foliar de tratamentos para o controle do míldio e da podridão-de-escamas de bulbos de cebola. Horticultura Brasileira, v.25, p.544-549, 2007.

Recebido em 12 de junho de 2009 e aprovado em 28 de novembro de 2009 